\title{
Um estudo sobre a aplicação de Algoritmos Genéticos no investimento em ações utilizando análise técnica
}

\section{André S. T. de Carvalho}

andrestc@dcc.ufrj.br,
Matheus R. M. de Almeida

matheusrma@dcc.ufrj.br,
João C. P. da Silva

jcps@dcc.ufrj.br

Departamento de Ciência de Computação, Instituto de Matemática, UFRJ,

21941-590, Rio de Janeiro, RJ

\section{RESUMO}

A análise do mercado de ações é um assunto desafiador que desperta o interesse de pesquisadores e especialistas em diversas áreas. Diferentes métodos foram desenvolvidos[4] para tentar prever as flutuações nos preços das ações visando maximizar os lucros de investidores e instituições financeiras. Uma metodologia muito utilizada, baseada no acompanhamento do movimento dos preços das ações ao longo do tempo, é a Análise Técnica[1], na qual investidores utilizam dados estatísticos e indicadores para tomar a decisão sobre a compra ou a venda de uma determinada ação. O objetivo deste trabalho é utilizar Algoritmos Genéticos (AG) para tentar determinar a melhor combinação de estratégias (e seus parâmetros) da Análise Técnica que maximizam o lucro de um aplicador.

Algoritmo Genético[2] é um método de busca e otimização inspirado na teoria da evolução de Darwin. Cada indivíduo da população representa uma solução candidata do problema que se deseja otimizar. No início de cada geração os indivíduos são avaliados por uma função de avaliação e, quanto melhor for sua avaliação, maior a probabilidade dele ser selecionado pelo operador de crossover. Este tem como objetivo combinar dois indivíduos para dar origem a dois novos indivíduos (seus "filhos"). Em seguida, o operador de mutação é aplicado aos indivíduos com o objetivo de garantir a diversidade da população. Para a nova população gerada pelos operadores, o processo se repete até que um critério de parada, por exemplo, número de gerações seja satisfeito. O mecanismo chamado de elitismo é utilizado quando se deseja garantir que os melhores indivíduos de uma geração sobrevivam na próxima. A solução encontrada pelo AG será sempre o melhor indivíduo da última geração.

Neste trabalho, utilizamos AG para combinar duas estratégias e seus parâmetros: cruzamento de médias móveis[1] e zonas de Índice de Força Relativa[1]. No cruzamento de médias móveis, temos: a média móvel simples (MMS) de $N$ períodos que é a média aritmética dos preços de fechamento de uma ação nos últimos $N$ dias, contando com o dia atual; e a média móvel exponencial (MME) que atribui um peso maior aos preços mais recentes. Dessa forma, a estratégia de cruzamento de médias móveis consiste em efetuar a compra da ações quando a MME de $N$ períodos cruzar, de baixo pra cima, a MMS de $M$ períodos, onde $N<M$. A venda é feita quando o cruzamento ocorre na outra direção. A estratégia de zonas do IFR utiliza o Índice de Forca Relativa (IFR)[3], indicador que varia de 0 a 100, e indica a venda quando o valor do indicador está acima de $S$ e a compra quando o valor está abaixo de $I$, com $0<I<S<100$. Foi utilizado também um mecanismo chamado de stop [1] que é responsável por efetuar operações automaticamente caso o preço da ação atinja um preço predeterminado.

A implementação foi feita em Java e o conjunto de dados utilizado é formado pelas cotações das ações da Petrobras de 2000 à 2013. O primeiro passo foi analisar o comportamento dos diversos parâmetros do AG: mutação (com e sem), elitismo (com e sem) e formas de representação dos indivíduos (binária e real). Para isto, consideramos apenas a estratégia de cruzamento de médias, na qual cada indivíduo representa 3 parâmetros: período da mme, período da mms e stop. A figura 1(a) é um exemplo de exploração feita pelo AG, nela podemos ver a convergência ocorrendo em um ponto central do espaço. Neste ponto está localizada uma grande quantidade de máximos locais (os mais vermelhos), como pode ser visto na figura 


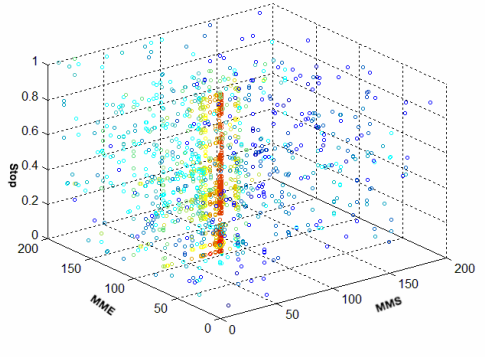

(a) Exploraçao

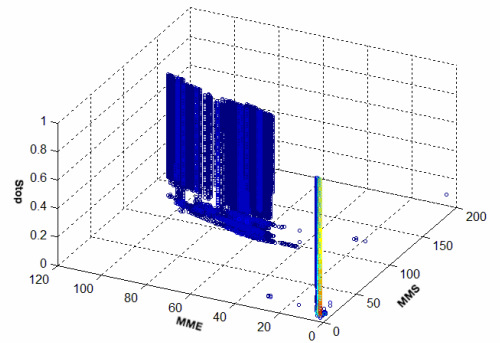

(b) Melhores soluções possíveis

Figura 1: Análise do Algoritmo Genético

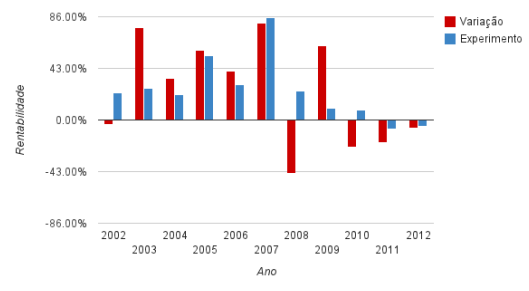

(a) Rentabilidade Ano A Ano

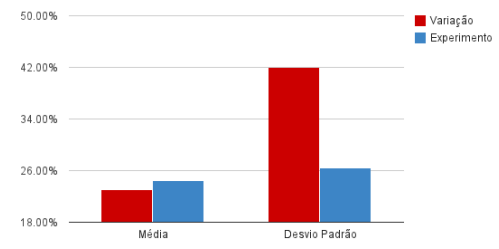

(b) Rentabilidade Média

Figura 2: Aplicação do Algoritmo Genético

1(b). A fim de aumentar o espaço explorado e tentar encontrar o máximo global implementamos um mecanismo de choque de mutação, responsável por alterar bruscamente a probabilidade de ocorrência do operador de mutação após sucessivas gerações sem melhora na melhor solução encontrada. Ao final deste passo, foi encontrado um conjunto de parâmetros do AG que julgamos ótimo: representação binária, com elitismo (5\%), com mutação (1\%), choque de mutação (10 gerações), $70 \%$ de probabilidade de crossover e 200 gerações como critério de parada.

Após esta análise, expandimos a modelagem da decisão de compra/venda das ações. Adicionamos a estratégia IFR e procuramos encontrar a melhor combinação desta com a estratégia de médias móveis por meio de operadores lógicos (AND, OR, XOR, NAND). As rentabilidades ano a ano podem ser visualizadas na figura 2(a), onde: variação corresponde a rentabilidade da ação naquele ano e experimento corresponde a rentabilidade obtida pelo AG. Na figura 2(b) é possível comparar a rentabilidade média e o desvio padrão anuais do experimento com a variação anual da ação. Os indivíduos que utilizam o operador lógico NAND obtiveram uma rentabilidade média superior a variação anual média do preco da ação com um desvio padrão $40.16 \%$ menor, ou seja, foi possível aumentar o lucro e diminuir o risco ao mesmo tempo. Futuramente planejamos utilizar múltiplas ações para compor uma carteira e acrescentar novos indicadores ao cromossomo.

Palavras-chave: Algoritmos Genéticos, Otimização, Ações, Análise Técnica

\section{Referências}

[1] E. Alexander, Como se transformar em um operador e investidor de sucesso, Editora Campus, 2004.

[2] L. Ricardo, Algoritmos Genéticos, Editora Ciência Moderna, 2012.

[3] J. Welles Wilder, New concepts in technical trading systems, Trend Research, 1978.

[4] W. Artur Filipe Ewald; B. José Alonso, "Redes neurais, lógica nebulosa e algoritmos genéticos: aplicações e possibilidades em finanças e contabilidade", JISTEM - Journal of Information Systems and Technology Management, São Paulo, 2010. 